\title{
Persistence pays off: Sir Charles Oatley and the scanning electron microscope
}

\author{
T. E. Everhart, ${ }^{\text {a) }}$ President \\ California Institute of Technology, Pasadena, California 91125
}

(Received 29 May 1996; accepted 9 August 1996)

\begin{abstract}
Shortly after World War II, Sir Charles Oatley initiated research at the Cambridge University engineering laboratories on what has evolved into the modern scanning electron microscope. While much of the research was actually conducted by research students under Oatley's supervision, he continually provided ideas, resources, and encouragement. He then was instrumental in having this instrument commercialized. His students often continued in the field for some time, making contributions both to the instrument and to its applications that led to improved performance and wider acceptance. This article attempts to capture some of the accomplishments of Sir Charles Oatley as seen by those who worked closely with him. The author believes that Sir Charles deserves the title: "Father of the Modern Scanning Electron Microscope." (C) 1996 American Vacuum Society.
\end{abstract}

\section{INTRODUCTION}

I first met Charles W. Oatley in late September, 1955. With my wife, Doris, I had arrived in Cambridge, England, to study for a Ph.D. degree under his supervision in the engineering laboratories of Cambridge University. Mr. Oatley, as we called him then, was somewhat formal, always neatly dressed, always helpful, yet a man of few words. He always addressed his students by their surname, and comported himself as the English gentleman he was. When I arrived, one student, Dennis McMullan, had completed his Ph.D. on the scanning electron microscope (SEM), a second, K. C. A. (Ken) Smith was starting his fourth year on McMullan's original instrument, which he had improved, and was starting to write his dissertation. A third student, O. C. (Oliver) Wells, was starting his third year, having built a second SEM from scratch. As the new student, I was to follow Ken Smith on the original instrument, sharing it with him during my first year.

Mr. Oatley had an impressive career before he arrived at Cambridge after World War II as a member of the academic staff. As an undergraduate, he had read natural sciences at St. John's College, Cambridge, and was a contemporary of Sir John Cockcroft, Sir Nevill Mott, and Louis Leakey. After a short time in industry, where he received a broad set of experiences, in 1927 he joined the staff of the Physics Department at King's College, London, under E. V. Appleton. He remained there until 1939, when he was invited to the Air Defense Experimental Establishment, later the Radar Research and Development Establishment, where he was first in charge of research and then was deputy head under Cockcroft. He was made director when Cockcroft left to work on the atom bomb. In 1945, he was invited by Trinity College, Cambridge, to become a fellow, and strengthen the postwar teaching of engineering.

Mr. Oatley was made a Reader in Electrical Engineering in 1954, which means he was second in the subject only to

${ }^{a)}$ Electronic mail: everhart@cco.caltech.edu the professor, who it turned out, was interested primarily in his own research. Mr. Oatley was revising the curriculum, introducing electronics and other more modern subjects, and stimulating research in the other staff as well as in his students. In short, he was busy.

Mr. Oatley became the Professor of Electrical Engineering in 1960, two years after I left Cambridge, and since then has been affectionately known to his students as Professor Oatley. He was elected a Fellow of the Royal Society in 1969, and retired from his chair in 1971, becoming Professor Emeritus and remaining active both at Trinity College and in the Engineering Labs for many years. He was knighted in 1974, and in 1976 became a founding fellow of the Fellowship of Engineering, now the Royal Academy of Engineering. Figure 1 is the official Royal Society photograph of him, probably taken about 1970 . His students and colleagues held symposia in his honor to help celebrate both his 80th and 90th birthdays. An avid gardener, he remained active until shortly before he passed away on March 11 of this year at the age of 92 .

A person's lifetime of accomplishments can properly be thought of as the sum of their own accomplishments plus the sum of their influence on other people: progeny, students, associates, and others. I cannot represent his progeny, the undergraduates he taught, or many others, such as many in this audience who have used the SEM. I can represent myself and try to represent research students who came before and after me, as I try to give you some idea of why Sir Charles Oatley, as I should refer to him now, deserves the title: "Father of the Modern Scanning Electron Microscope."

\section{RESEARCH AND EDUCATION RATIONALE}

In 1982, Sir Charles published an article in the Journal of Applied Physics entitled "The early history of the scanning electron microscope." 1 After discussing the work of Knoll and collaborators, Von Ardenne, and Zworykin, Hillier, and Snyder, who were all excellent people, but did not produce a viable SEM, he posed a question: "Why, in the face of the 


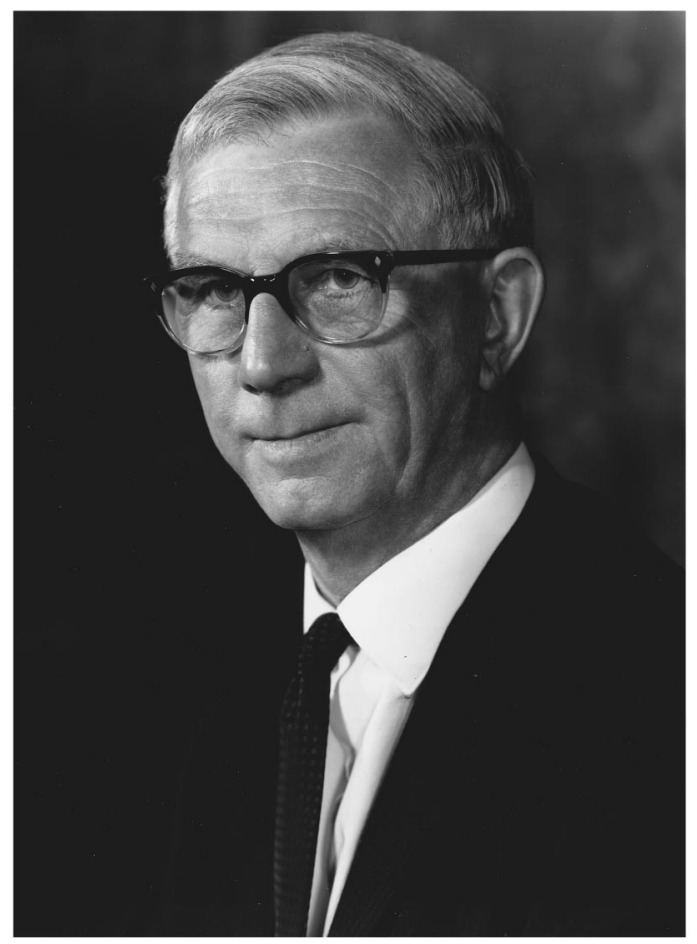

FIg. 1. Professor Sir Charles Oatley, OBE, FRS, charter member, Royal Academy of Engineering.

discouraging results that had hitherto been obtained, did I think it worthwhile to reopen the matter in 1948?' He answered the question by describing the conditions in the engineering laboratories at that time, and providing his own views on university research. These conditions and views provide an important insight into the man, and his impact on engineering at Cambridge, as well as on the SEM. I should like to quote a few paragraphs from that article to illustrate.

"Before the war, graduates from the Cambridge University Engineering Department normally left immediately after obtaining their first degree and went into industry to take a graduate apprenticeship which would later qualify them for membership of a professional Institution. Very few remained in the Department and such research as was done was carried out largely by members of the teaching staff. In light-current electrical engineering it was confined almost entirely to problems relating to circuits.

By 1945 there was general agreement that the prewar pattern could no longer meet the needs of rapidly advancing technology and that a considerable research effort should be built up in the Cambridge Engineering Department. To assist with this program I was appointed to a lectureship in engineering. At the time of my appointment I was in charge of the army Radar Research and Development Establishment, in which I had worked for the past six years. Prior to that I had been a lecturer in a university physics department so it was natural that, in thinking of possible future research projects, I should look with favor on those which could be broadly classified as applied physics.

From a different point of view, a project for a Ph.D. stu- dent must provide him with good training and, if he is doing experimental work, there is much to be said for choosing a problem which involves the construction or modification of some fairly complicated apparatus. Again, I have always felt that university research in engineering should be adventurous and should not mind tackling speculative projects. This is partly to avoid direct competition with industry which, with a "safe" project, is likely to reach a solution much more quickly, but also for two other reasons which are rarely mentioned. In the first place, university research is relatively cheap. The senior staff are already paid for their teaching duties and the juniors are Ph.D. students financed by grants which are normally very low compared with industrial salaries. Thus the feasibility or otherwise of a speculative project can often be established in a university at a small fraction of the cost that would be incurred in industry. So long as the project provides good training and leads to a Ph.D., failure to achieve the desired result need not be a disaster. (The Ph.D. candidate must, of course, be judged on the excellence of his work, not on the end result.) The second reason is rather similar. A Ph.D. student stays at the university for about three years and his departure provides a convenient point at which the promise of his project can be reviewed. If it seems unlikely to succeed, it can be discontinued without the dissatisfaction and discouragement which sometimes attends similar action in industry.'"

\section{BRIEF HISTORY}

Oatley knew of innovative work by A. S. Baxter in the Cavendish laboratory on a secondary electron multiplier with beryllium-copper dynodes, which could be operated successfully in a demountable vacuum system. This new electron multiplier could amplify the nanoampere and smaller electron currents expected in the SEM, and overcome one of the problems faced by previous investigators. He also knew of many electronic advances made during World War II, which might improve performance of the SEM. He assigned the task of building a new SEM to Dennis McMullan, who was returning to Cambridge for Ph.D. work after five years in industry working on radar, cathode ray tubes, and analog computers. Oatley had acquired a loft full of war surplus valves, cathode ray tubes, meters, and other electrical components, as well as surplus vacuum pumps and equipment. There was also access to an excellent machine shop with skilled machinists, but there was little money, and he and his research students had to rely on their own ingenuity. They were also fortunate to have the skilled help of Leslie Peters, technical assistant in the department. Peters spent much of his life helping develop the SEM at Cambridge. On his retirement, Oatley proposed him for an honorary MA, which was granted.

McMullan built an electrostatic electron microscope, including the electron lenses and a $40 \mathrm{kV}$ stabilized power supply. He also built a cathode ray tube display unit, added scanning coils to the microscope, and he got all this electrical, mechanical, and vacuum equipment to work as the desired system! Those who followed him are grateful for his 


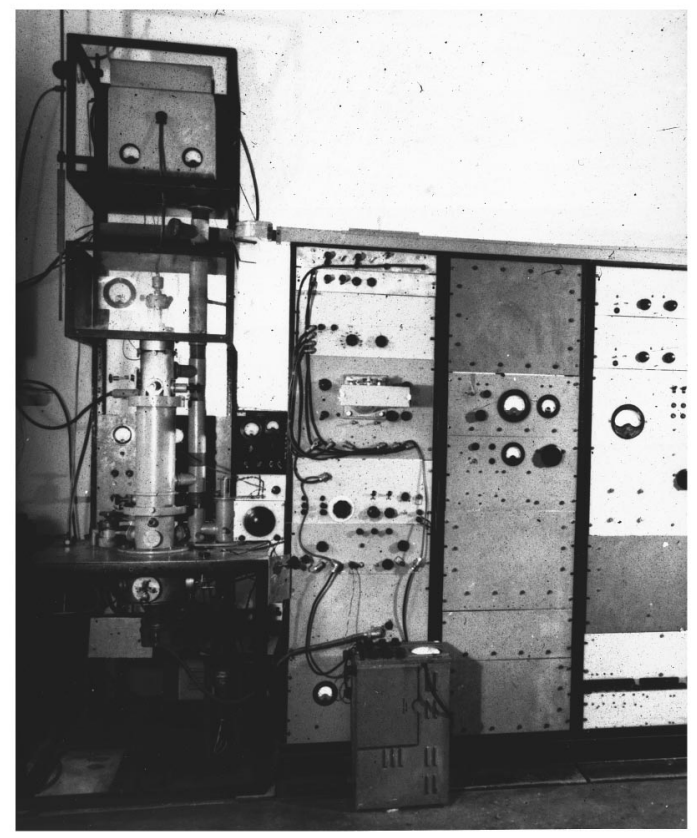

FIG. 2. D. McMullan's scanning electron microscope, as modified by K. C. A. Smith. Photograph taken about 1955.

ingenuity and hard work, for had he failed, the story of the scanning electron microscope would be very different. Figure 2 is a photograph of his microscope in Scroope House, where much of the early work took place.

McMullan examined samples with the scanning beam incident obliquely on the surface, in order to increase both the number of reflected primary electrons and to produce more contrast than could be obtained at normal incidence. Ken Smith believed that secondary electrons actually produced more of the video signal that was used to modulate the intensity of the display cathode ray tube, and I carried out a series of experiments to determine what fraction of the video signal was due to secondary electrons, and what fraction was due to the reflected electrons. But I digress: this talk is about Sir Charles Oatley, not about individual contributions to the SEM by particular research students.

McMullan's microscope was promising enough that Oatley asked Ken Smith to carry on. Ken improved the reliability of the microscope, and investigated several fields of application. $^{2}$ This showed how the SEM was complementary to the transmission electron microscope (TEM), and drew some attention. However, the resolution was a few hundreds of angstrom units for the SEM versus 10 or 20 for the TEM. The fact that sample preparation was minimal to zero for the SEM compared to replica preparation for the TEM did not seem important, especially to people who had spent a good deal of time learning how to prepare replicas. This hard won knowledge became obsolete if one used the SEM! Oatley persevered in his faith, and each student who operated a SEM spent some time extending the applications to help prove the worth of the instrument.

For example, Oliver Wells showed that one could examine fibers without burning them, a problem in the TEM, and

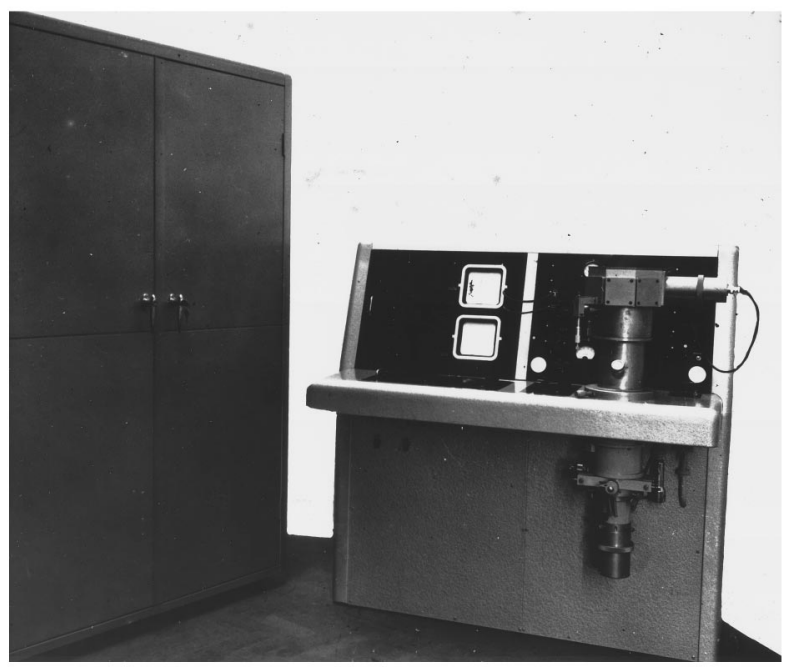

FIG. 3. The Canadian Pulp and Paper Research Institute SEM, constructed by Dr. K. C. A. Smith at Cambridge University engineering laboratory. Photograph taken in Cambridge by Les Peters about 1957 or 1958.

he examined the inside bore of spinnerets used to spin artificial fibers, impossible in the TEM. I looked at $p$ - $n$ junctions, and developed an understanding of voltage contrast as well as electron beam induced currents produced by the scanning electron beam. Richard Thornley examined powders. Others continued this tradition.

Keeping an electron microscope operating at peak efficiency, especially one built with war surplus components, was not always easy. In particular, I had difficulty with the first electronic amplifier that followed the electron multiplier. The first dynode of the electron multiplier had to be a few hundred volts positive with respect to the sample, which was normally grounded. Each succeeding dynode was a few hundred volts more positive yet. By the time the final collector of the multiplied current was reached, the potential was several thousand volts positive, and the amplifier and its power supply had to float at this potential, amplifying the signal so that when it came through a high voltage capacitor to ground, the signal would dominate over any noise introduced at that step. I sought a much simpler solution to this problem.

Mr. Oatley had suggested a fast plastic scintillator called Pamelon used in high energy physics for particle detection to Ken Smith for his water vapor cell. He procured a supply of this material for me to use in contrast experiments. This scintillator proved useful for transmitted and reflected electrons, and with a special detector that I constructed so that the scintillator material could be at $10-15 \mathrm{kV}$, it proved possible to detect secondary electrons in this way as well. By guiding the light produced to a photomultiplier, a noise free detection system useful for any of the three signals resulted. Richard Thornley later carried out detailed measurements on the appropriate voltage needed to accelerate the secondary electrons for noise free operation, to characterize the detector more completely. Each of Oatley's graduate students could undoubtedly recite similar suggestions he made that helped them solve problems they faced. 


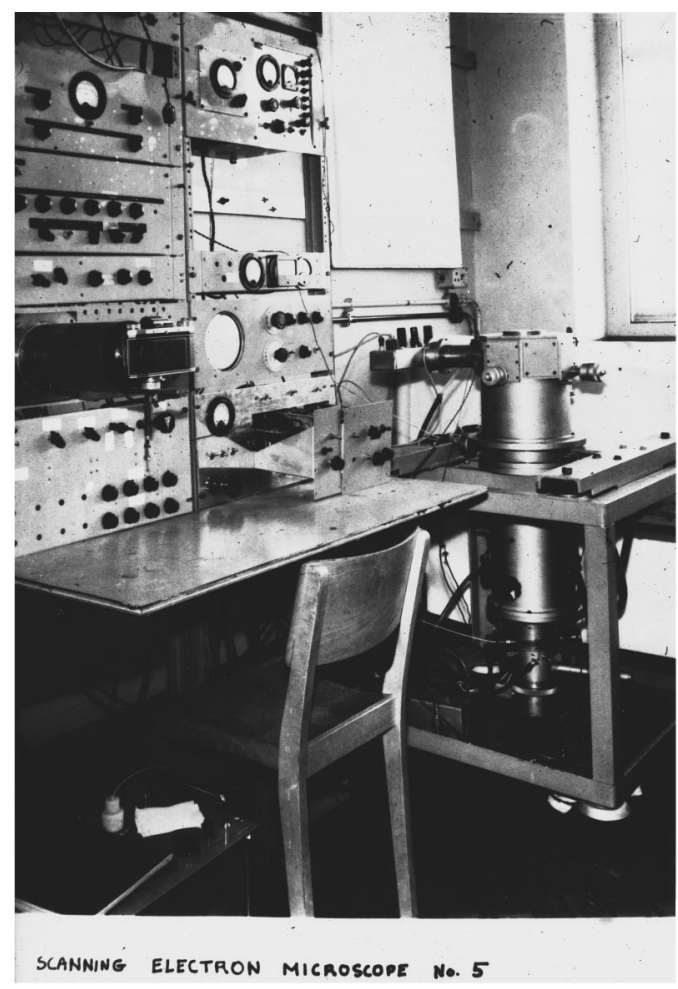

FIG. 4. High resolution SEM constructed by R. F. W. Pease. Photograph taken in 1963 by Les Peters.

After Ken Smith received his doctorate, Oatley also arranged for him to design and construct an improved SEM for the Pulp and Paper Research Institute of Canada. This instrument, shown in Fig. 3, had magnetic lenses, and incorporated the improved detector mentioned above. Its performance gave confidence that a stable, reliable instrument could be built for routine work. It performed well in Canada for a decade or more.

Garry Stewart, Fabian Pease, Alec Broers, and Phillip Chang were the final four doctoral students that Oatley accepted, although the latter three finished their dissertation under Dr. W. C. Nixon, who joined Oatley as Assistant Director of Research in October, 1959. Stewart built an improved instrument, and studied basic mechanisms in ion sputtering, watching the process dynamically. Pease constructed a high resolution SEM using a much improved magnetic lens design, and improving many other aspects of the instrument as well. He held the resolution record for the SEM for several years. A picture of his instrument is shown in Fig. 4. Broers inherited Stewart's instrument and studied selective ion beam etching. Stewart meantime went to work for Cambridge Instruments Company, and played a major role as that company commercialized the Stereoscan SEM. Chang has had a distinguished career at IBM, and recently has developed a pocket-sized SEM column.

\section{EDUCATION AT CAMBRIDGE}

In order to appreciate Mr. Oatley's considerable influence, it is necessary to understand the university system in which he operated. Cambridge University is a collection of colleges and members of the university are generally also members of a college. As such, they contribute to and interact with members of the college, as well as with their own university department. In Mr. Oatley's case, he was both a fellow of Trinity College and a member of the engineering faculty. Individual supervision of undergraduate students was arranged through the college; lecture classes were taught in engineering. Students were expected to learn the material, but were examined on it only at the end of the year, a preliminary exam being taken at the end of the first year, and the Tripos exams at the end of their second and third year. More studying often went on during vacations, which were long, than during term time when lectures were given and there were many student activities.

At that time, there were few lecture courses for graduate students, and they were purely voluntary. Graduate students were given great freedom, but also considerable responsibility. Research supervisors would advise, point you in the right direction, refer you to articles to read, but the detailed knowledge you had to dig out for yourself. It took considerable discipline to make each day count.

The normal work week was Monday through Friday, plus Saturday morning. Morning coffee at about 10:30 a.m. was when I could count on finding Mr. Oatley for a few moments, to ask a question, gain permission for a purchase, or discuss a point. All the research students gathered there, as did several members of the staff. A good deal of informal questioning, discussion, and learning took place then. Mr. Oatley made many suggestions during these moments that helped my research move forward. He also would ask about my wife and daughter. Perhaps because there were very few married students at Cambridge in those days, his wife, Enid, would look in from time to time on my wife and infant daughter, often bringing a little gift, a word of cheer, and confirming that the entire Everhart family was important to both the Oatleys.

One morning at coffee, Mr. Oatley asked me about a recent development in traveling wave tubes, a topic of my earlier research at the Hughes Research Labs. A lecturer in the department who had some radar experience during WW II interjected that he didn't know why Oatley asked me, a lowly research student, about such a topic. Mr. Oatley, with a smile, responded that since I had three publications on the subject, he thought the question was appropriate. We then continued our discussion, while the lecturer listened. Mr. Oatley treated people well, respected them for what they knew, and was able to educate them when they needed it.

Because of his age (over 50 at the time) and distinguished bearing, both the academic and electronic shop staff often referred to Mr. Oatley as "Uncle", when he was not present. He never let on that he knew this, until one day when two members of the academic staff were having a discussion about a difficult question. He was asked for advice, solved the problem on the spot, and then left the room. As they were expressing wonder and appreciation about this feat, he stuck his head back through the door, and reportedly said: "Uncle 
is a cagey bird", and then left. This added to his legend as a leader who was aware of what was going on around him!

\section{PERSISTENCE PAYS OFF}

Even in 1960 detractors well outnumbered champions of the SEM. Indeed, Mr. Oatley himself still defended his program largely on the grounds of the SEM being a valuable educational vehicle in that mastering it required developing competence in a wide variety of disciplines including electron optics, circuitry, signal processing, mechanical engineering, high voltage engineering, and, often, solid state physics. Indeed, the SEM faced competition from the transmission electron microscope because the latter was perceived to be much simpler and had far better resolution. In addition, the TEM could operate in reflection, which allowed examination of surfaces at higher resolution than that obtained with the SEM. Nonetheless, there were a growing number of applications for which the reflection and replica techniques were impractical (e.g., the in situ examination of surfaces undergoing changes or very fragile surfaces) and, although not appreciated by professional microscopists at the time, the convenience (minimal specimen preparation) and extraordinarily lifelike images made believers out of those who had access to the SEM. V. E. Cosslett, who led the electron microscope research group at the nearby Cavendish laboratory, recognized that the scanning operation allowed decoupling of the mapping operation from the contrast operation so that the information from the sample did not have to be focused. This allowed Dr. Peter Duncumb on Cosslett's team to develop the scanning electron $\mathrm{x}$-ray microanalyzer (which mapped elemental content by collecting characteristic $\mathrm{x}$ rays).

Mr. Oatley pressed hard for the commercialization of the SEM. He hoped Metropolitan Vickers, a company that made electron microscopes, would make and sell them, but this came to naught. Drs. Ken Smith and Bill Nixon persuaded the chief development engineer of the Cambridge Instrument Company that, in addition to the scanning X-ray microprobe, mentioned above, the company should manufacture the SEM as well. Sir Charles received permission from Metropolitan Vickers to turn elsewhere, then approached the managing director of the Cambridge Instrument Company, and the first commercial SEM was under way. Since the mid 1960's, commercial SEMs have enabled many people to see the world we live in with more clarity and detail, and to both see, and then make, smaller devices which have benefited mankind.

\section{OATLEY'S SEM STUDENTS}

The people who worked on the SEM under Sir Charles Oatley have had successful careers, often using the expertise they learned in Cambridge. Dennis McMullan, after a successful career at Imperial College, London, and at the Royal Greenwich Observatory, is carrying on research in Cambridge during his retirement. Ken Smith helped Dr. V. E. Cosslett develop a high voltage TEM in the Cavendish, and later was a member of the team that developed a high resolution electron microscope. He became a Reader in the engineering laboratory, and is now retired. Oliver Wells has had a successful career in industry, for many years at IBM, and has written a book on the SEM, as well as made many contributions to its operation and applications. I was active in the field for about twenty years while a professor at Berkeley, and more recently have been active in academic administration. Peter Spreadbury, who developed a simplified SEM as a Master's degree project, is a lecturer at Cambridge. Richard Thornley has had a successful career at IBM, and more recently at Storage Technology. Garry Stewart worked for a considerable period of time at Cambridge Instruments Company and, more recently, at deBeers, where he has put his considerable expertise at instrumentation to good use. Fabian Pease is a professor at Stanford University, after a successful period at Bell Laboratories. He has made important contributions to a host of fields, including electron beam micro fabrication and commercial instruments for this purpose. Alec Broers had a very successful career at IBM, rising to become an IBM fellow and department manager. He returned to Cambridge, becoming Professor of Electrical Engineering, head of the engineering laboratories, Master of Churchill College, and in October 1996 became the Vice Chancellor of Cambridge University.

Sir Charles Oatley told me on a recent visit to Cambridge that he took considerable satisfaction in the accomplishments of his students, such as Ian Ross, an early student who became President of Bell Labs. He would be delighted that Alec Broers will become the first engineer to ever lead Cambridge University. Sir Charles was a modest man, who sent his students off to conferences to give papers, who immersed himself in bettering his university while others gave the talks, and who quietly paved the way for others. Through his ideas, his encouragement, his provision of resources, and his push for a commercial SEM, I believe that Sir Charles Oatley truly deserves the title: "Father of the Modern Scanning Electron Microscope.',

${ }^{1}$ C. W. Oatley, J. Appl. Phys. 53, R1-R13 (1982).

${ }^{2}$ The contributions mentioned in this article are documented in Ref. 1 in more detail, and are not included here to save space.

${ }^{3}$ I am indebted to D. McMullan, K. C. A. Smith, O. C. Wells, R. F. W. Pease, and A. Broers for help in preparing this manuscript. I have also referred to obituaries that appeared in the London Times, The Guardian, and Nature. 